\title{
Peer observation in professional development: Occupational therapists' perceptions
}

\section{Deborah Davys, Jacqui McKenna, Ellen Tickle}

Aims: Peer observation of practice is used to promote reflection and facilitate personal and professional development. However, there appears to be no published research on the use of peer observation by occupational therapists working in higher education. This action research project explored the perceptions of occupational therapy staff within a higher education setting towards the use of a peer observation of practice scheme.

Methods: All colleagues within a directorate of occupational therapy were invited to complete a questionnaire. Additionally, five staff were invited to take part in semi-structured interviews and core themes were identified following thematic analysis, typified by grounded theory.

Findings: Staff used a range of methods to support professional development, including peer observation. Key themes identified were the concept that peer observation has both positive and negative connotations, that feedback must be carefully managed, that the relationship between observed and observer is important and that staff want clear ground rules for peer observation schemes.

Conclusions: Findings indicated the need for further research into peer observation and how such a scheme could be formally implemented.

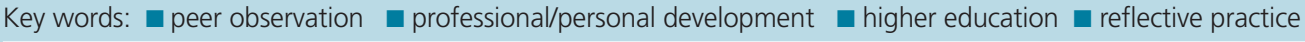

Submitted 13 March 2008; sent back for revisions 10 April; accepted for publication following double-blind peer review 12 May 2008

$\mathrm{A}$ ccording to Kuit and Reay (2001), those teaching in higher education (HE) are expected to evaluate their practice and provide a high quality educational experience for their students. This position is supported within the United Kingdom (UK) by the Government White Paper: 'The Future of Higher Education' (Department for Education and Skills, 2003) which suggests that quality teaching practice within universities needs to be recognized, rewarded and shared. Peer observation is one method that may be used to promote reflection upon practice and has relevance in both clinical and managerial contexts of practice, as well as education (Davys and Jones, 2007). Professional education programmes feature reflective practice, which is demanded by benchmarking systems and the Knowledge and Skills Framework (Department of Health, 2004) as evidence of quality education provision.

All reflective structures are based on the three basic elements of experience, reflection and action, with some models encouraging the reflector to think about what might be done in the future. A simple three-stage process of reflection asks three key questions: 'What? So what? and Now what?', the focus being on solving problems and taking action (Borton, 1970). Boud et al (1985) emphasize the importance of the reflective process as a means for learners to explore their experiences, enabling an understanding of the learning process and its impact, and leading to new understanding and deeper learning. Therefore reflection is a systematic way of thinking about experiences and using them to change practice or confirm that our practice is safe and effective. Educators and practitioners alike need to be reflective and develop a repertoire of skills and strategies that support critical enquiry and selfreflection. According to Larrivee (2000: p.294), if this is not undertaken, individuals will remain:

'trapped in unexamined judgments,

interpretations, assumptions and expectations."

According to Schon (1983) reflection can be performed both 'in action', (while the task is being carried out) and 'on action', (once the task is completed). Reflection can be done individually or in
Deborah Davys is Lecturer in Occupational Therapy, Jacqui McKenna is Senior Lecturer in Occupational Therapy, and Ellen Tickle is Lecturer in Occupational Therapy; Directorate of Occupational Therapy, University of Salford, Allerton Building, Frederick Road Campus, Manchester, M6 6PU

Correspondence to: D Davys

Email:

D.Davys@salford.ac.uk

Tel: 01612952869

Fax: 01612952432 
groups, and can be verbal (via supervision, conversation) or written (via journals, diaries). There are many methods of evaluating classroom activity such as the monitoring of student achievement, the collation of data and production of reports, supervision, mentoring, appraisal, student evaluation forms and surveys, all of which are valid and well-evidenced strategies that may be used in quality assurance in practice and education (Biggs, 1999; Tight, 2004).

\section{Peer observation}

Peer observation is not a new concept but one that has been part of university practice over the past 10 years. Its primary agenda was that of raising the quality of teaching and sharing good practice with colleagues. In general terms, it involves peers observing each other's practice with the aim of improving practice and facilitating personal and professional development (Shortland, 2004). There are various models of peer observation, such as two colleagues observing each other with an agreed agenda followed by a constructive discussion. Variations on this model may involve colleagues working in groups of three or using video extracts that can be discussed against set criteria and from which future development plans are made (Cotton, 2001). In essence however, the process usually involves the stages of selecting a peer as observer, agreement on the areas of practice to observe, the observation, reflection upon the experience, a feedback meeting and action plan/follow-up (Davys and Jones, 2007).

Peer observation is however, a process that requires careful management in terms of the purpose of observation and how it is put into operation. It can be used as an agenda for management and control or as a developmental tool for both individuals and departments (Hammersley-Fletcher and Orsmond, 2005). Peer observation has been found to be of greater value when used for formative rather than summative purposes, yet one of the main barriers to using this strategy is the anxiety it raises among staff (Swain, 2007). Some consider the process undesirable as it encounters the issue of power imbalance that may exist between individuals. The process could be used in a judgmental way or conversely, may be diluted to serve as a mutually supportive praise session for friends (Hammersley-Fletcher and Orsmond, 2005). As such, peer observation needs to be objective, constructive and requires sensitive planning and management, especially around the provision of feedback (Peel, 2005).

\section{A higher education setting}

The practice of peer observation can be used as a valuable tool to promote self-awareness, facilitate the identification of developmental needs and to support debate around good practice in higher education. This is in addition to providing a means of accounting for and improving teaching and learning quality. Critical analysis and feedback will attempt to assist with the exploration and challenging of attitudes, feelings, values, habits and assumptions, which may in turn facilitate the development of new perspectives and practices (Hammersley-Fletcher and Orsmond, 2004).

At present, there appears to be no published research on the use of peer observation by occupational therapists working in higher education. There is however, relevant literature within the profession that calls for professional development and outlines the responsibility of the therapist to engage in activities that demonstrate the enhancement and quality of practice whatever the setting. This view is supported by the College of Occupational Therapists (2002), the professional body, who within their position statement on lifelong learning, refer to the significance of continuing personal and professional development for all members; stating that this is a requirement across the spectrum of practice. It is the expectation of the College that members will participate in supervision, mentoring, appraisal, personal development activities and reflective practice. As such, occupational therapists - both in teaching and practice - have a right and a responsibility to engage in both formal and informal learning activities. From 2007, occupational therapists and other health professionals in the UK are required by the Health Professions Council to maintain a current record of Continuing Professional Development (CPD) so as to maintain their eligibility for registration.

\section{AIMS}

The setting for the study was a directorate of occupational therapy based within a university in England. There was no formal policy or procedure for the use of peer observation of teaching practice within the Directorate although some staff used an informal procedure. However, some staff were required to carry out a formal procedure as part of their studies for a Postgraduate Certificate in Higher Education Practice and Research, and it was as a result of this programme that the authors undertook this study. The aim was to enhance the understanding of staff attitudes and perceptions of peer observation of practice as a preliminary step to further departmental discussion on the possibility of implementing policy and procedure for peer observation of practice, which is considered to be of significant importance to those teaching in higher education (Kuit and Reay 2001). 


\section{METHODS}

The authors chose to use the first cycle of an action research project to explore the perceptions of staff within a directorate. Action research is generally understood to be a tool for enhancing, practice in an educational context. It involves reflection on practice to support and develop prac-tice. Action research is considered to be a method of self-reflective enquiry which is collaboratively undertaken by participants involved in a particular situation to better understand and improve their practice (Kember, 2000). As such, all staff within the directorate were invited to participate in the research project.

\section{Ethical issues}

Before this project was undertaken, ethical approval was gained from the University ethics committee. All 17 staff members of the directorate were provided with an explanatory letter giving information on the project and were invited to complete the questionnaire. Those participants who agreed were considered to have given informed consent when they returned the questionnaire. The five staff members who agreed to take part in the interviews were given a written reminder of the aim of the interview and were asked to provide written consent which re-iterated the right to withdraw and retract consent at any point in the process. The issues of anonymity, confidentiality, the storage of data and dissemination were also addressed (Bell, 1999).

\section{Data collection}

Two types of data collection tool, a questionnaire and semi-structured interviews, were used to add to the depth and quality of data collected (Hammell et al, 2002). Information was collected from the whole staff group (17 colleagues) in keeping with the action research ethos.

\section{Questionnaires}

The questionnaire consisted of closed questions to gain relevant factual data. A pilot questionnaire was answered and assessed by two 'critical friends' (Bambino, 2002), ensuring that the questions were clear and valid (Bell, 1999), related to the research aims, and fostered involvement in the action research process. The critical friends were from the same directorate. Minor amendments were made to the questionnaire following feedback from colleagues. Completed questionnaires were returned anonymously in pre-addressed envelopes.

\section{Semi-structured interviews}

In addition to the questionnaire, semi-structured interviews were conducted with a purposive sample of five staff members (Table 1). Further staff were not invited to participate in the interviews owing to the time restrictions of the study however, this number was considered sufficient for this type of research (Polit et al, 2001). Staff members who had been working in the directorate for varying lengths of time, including the longest and shortest serving staff members, were chosen to gain a cross section of opinions and beliefs. The questions used within

Table 1.

Semi-structured interviews questions

1. How long have you been part of the teaching team within this directorate?

2. What were your previous posts before joining the teaching team?

3. What teaching qualification do you hold?

4. What methods do you use to support professional development in relation to your teaching practice?

5. Has your teaching has ever been observed by someone in the teaching team for the purpose of professional development?

6. What do you know / understand about peer observation of teaching in relation to professional development?

7. What do you think about peer observation being linked to professional development?

8. What is your attitude towards the idea of being observed by a peer for the purpose of professional development?

9. What are your views about a peer making comment on your teaching practice for the purpose of professional development?

10. In your opinion, is there anything that would make the idea of being observed by a peer acceptable to you?

11. In your opinion, is there anything that would make the idea of being observed by a peer less acceptable to you?

12. Do you feel that there are any benefits to being observed by a peer in relation to professional development?

13. Do you feel there are any disadvantages to being observed by a peer in relation to professional development?

14. What is your response to the idea of a peer observation review system being introduced within this directorate to support professional development? 
the interview process were shaped by the literature, observation and the authors' views on the peer observation process.

The interview questions were also checked by critical friends (Bambino, 2002) to ensure that they were clear, met the research aims and supported collaborative research. This process also served to support internal validity (Robson, 2002). Before the final questions were established, further amendments were made. The questions were open-ended and aimed to explore the attitudes, values and beliefs of staff (Ruane, 2005) on the use of peer observation of practice to support professional development in a specific higher education setting.

The interviews were held at the university where the Directorate involved with the study was based. Each interview was audio-taped and brief notes were made during the session by the interviewer who was

Table 2.

Quantitative data generated from the questionnaire

\begin{tabular}{|c|c|}
\hline & Respondents \\
\hline Number of questionnaires sent out & 17 \\
\hline Number of questionnaires returned & 13 \\
\hline \multicolumn{2}{|l|}{ How many staff have a teaching qualification } \\
\hline Staff with a formal teaching qualification & 3 \\
\hline Staff completing a formal teaching qualification & 2 \\
\hline Staff without formal teaching qualification & 8 \\
\hline \multicolumn{2}{|l|}{ Peer observation } \\
\hline Staff who have been formally observed while teaching & 7 \\
\hline Staff who have not been formally observed while teaching & 3 \\
\hline Staff who have been informally observed while teaching & 3 \\
\hline $\begin{array}{l}\text { Staff required to have teaching formally assessed for formal } \\
\text { teaching qualification }\end{array}$ & 5 \\
\hline \multicolumn{2}{|l|}{ Staff reaction to being observed } \\
\hline Feelings of anxiety/stress & 7 \\
\hline Enjoyed the process & 4 \\
\hline Equal feelings of anxiety and pleasure & 2 \\
\hline \multicolumn{2}{|l|}{ Reported change in teaching practice following observation } \\
\hline Improvement in teaching & 8 \\
\hline Skill development & 5 \\
\hline \multicolumn{2}{|l|}{ Disadvantages to being observed } \\
\hline None & 4 \\
\hline Feeling anxious/threatened & 2 \\
\hline Need to attach formulate ground rules for observation & 5 \\
\hline Equal concern to formulate ground rules and feeling anxious & 2 \\
\hline $\begin{array}{l}\text { Number of staff willing to take part in process if formally } \\
\text { introduced }\end{array}$ & 13 \\
\hline
\end{tabular}

also a member of staff within the Directorate. The same interviewer undertook all interviews and transcribed key points from the tapes.

\section{Data analysis}

Once interviews were transcribed, the authors performed manual content analysis to identify themes (Burnard, 1991). Main themes were then clarified with critical friends, supporting collaborative feedback and triangulation (Bambino, 2002). Themes were also verified by cross-checking field notes kept from each interview.

\section{FINDINGS}

The questionnaire was answered by 13 of the 17 colleagues. The quantitative data generated from the questionnaire is shown in Table 2. Following content analysis of the interviews, five main themes emerged, which were present in all interviews. The preliminary findings from the questionnaires support the themes that arose from the interviews and provides evidence of content validity (Robson, 2002).

\section{Peer observation is positive}

This theme emerged in all interviews and incorporates the sub-theme that there are advantages to being observed by a peer. The advantages highlighted were that peer observation enables the individual to learn and develop in a professional sense, that it leads to reflection about one's own practice, and that it enhances the quality of teaching. Interviewee 1 stated:

'It can lead to independent reflection, that would help you learn or explore more about your own practice."

Interviewee 3 stated:

'It's a good thing, its appropriate and feasible and positive from a CPD perspective."

\section{Relationship between the observed and observer is important}

This theme was prevalent in all of the interviews. Staff wanted to present a professional front however, it was clear that colleagues' level of comfort in peer observation would be dependent upon who was observing. Some colleagues made further comment after the tape recorder was switched off that would further support this view, however, only those comments made on tape are reported. Interviewee 3 stated:

'It could be difficult if there was friction between individuals, it could lead to unfairness and reduced objectivity....it could reduce your confidence and make people feel vulnerable." 
Interviewee 4 stated:

'You need to trust and have confidence in the person making the observations, you need to value their opinions...there are some people I would prefer not to have as an observer as I would not respect or value their opinion.'

\section{Purpose of a peer observation scheme and how it will be put into operation}

This theme suggests that participants want some degree of control over a peer observation scheme. The terms and conditions colleagues were concerned about included the purpose of the observation, who will observe and what will happen to the information gathered. Other areas of concern were highlighted, such as how often staff would be observed and whether it would be a voluntary or mandatory process. Present in this theme was the opinion that staff should be able to decide which session is observed, where and when the observation will take place. Also highlighted was the desire for confidentiality and that performance should not be linked to pay. Interviewee 1 noted:

"It would be better if the assessor is experienced... you need to feel confident in the person assessing you... better if you can choose or have a completely independent person...you need to respect the observer...I would want to know the purpose of why I was being observed.... is it for managerial purposes? I don't want any hidden agenda... is it a rod with which to beat me?'

and:

'I would agree to it being introduced into the directorate but would want to know the rationale, how, when, the outcomes and regularity, I would want some control and be clear about these things'

\section{Peer observation has negative aspects}

The view that peer observation has negative connotations arose in all interviews. Data collated from the interviews and questionnaires suggest that being observed is perceived to be anxiety provoking, stressful and may be related to the fear of being seen in a poor light by colleagues or exposed in what could be an embarrassing way. This theme is related to other identified themes, such as 'the relationship between the observer and the observed is important' and 'the purpose of a peer observation scheme and how it can be put into operation'. This is indicated by interviewee 3 :

'It's anxiety provoking...someone watching you...sessions do not always go well and you could be exposed as a terrible teacher...it could affect relationships between team members'.

These comments also suggest that the actual process of being observed affects performance in a detrimental way. Some colleagues considered both positive and negative aspects of peer observation within the same sentence. For example, interviewee 5 noted:

'It's nerve racking, horrendous but it makes you aware of how you present to students and its about quality".

This may suggest that colleagues give equal weight to both the negative and positive consequences of a peer observation scheme, a view supported by Blackmore (2005) who found that although staff within a higher education setting initially found the observation process anxiety provoking, most were willing to continue and found the process beneficial to their practice.

\section{Feedback must be carefully managed}

Although this theme is reiterated within 'the relationship between observed and observer is important' and 'the purpose of a peer observation scheme and how it can be put into operation', the need for sensitive and constructive handling of feedback was consistently expressed by individuals. Participants explained that they would want feedback to be managed sensitively, to be objective and constructive. Interviewee 3 expressed the desire for honest feedback but recognized the possible negative impact upon a relationship:

'Feedback needs to be honest... maybe it would be more objective if it was from someone outside the directorate...I could take it on board then and no-one else on the team would know.'

Interviewee 1 noted:

'Feedback needs to be done very carefully, you need the right skills to do this, it needs to be honest but end on a positive note.'

\section{DISCUSSION}

It is clear from the results of this preliminary study and further review of the literature, that staff responses to the idea of a peer observation scheme being introduced within a department are complex and multifaceted. It was interesting to note that while the findings of this study support the literature in this area, the possible assumption that longer serving members of staff may be less amenable to the idea of a peer observation review scheme being introduced was unfounded. Staff had similar perceptions and concerns irrelevant of the amount of time they had spent in a higher educational setting, which could be seen as an alternative perspective from Sweeney et al 
(2001a) who suggest that a peer observation scheme is of particular benefit to newly qualified staff.

\section{Positive aspects}

The positive aspects of peer observation cited in the study include the opportunity it provides for selfreflection and how this process can positively impact on teaching skills. These findings are supported by Hammersley-Fletcher and Orsmond (2005) who claim that peer observation can be used to promote reflection upon practice, which enhances self-awareness and meets the individual's developmental needs. There are also further benefits, not directly mentioned by participants but evident in the literature. Driscoll and Teh (2001), for example, state that peer observation of practice is significant in relation to personal and professional development because it demonstrates to practitioners in all spheres that learning about their everyday practice is ongoing. Similarly, observation can be an aid to the development of selfawareness and use of critical thinking (Cotton, 2001).

There are also practical benefits that may arise out of peer observation of practice. Sweeney et al (2001a) found that the use of a peer observation scheme supported the recruitment and retention of staff, among those who are more recently qualified. Cosh (1999) states that staff working together in such a capacity may experience increased job satisfaction and that the process will serve as a mechanism to avoid staff becoming isolated within practice and guard against practice becoming routine. On a similar theme, Shortland (2004) suggests that observation of practice can support the establishment of lifelong learning as part of CPD and that as this process incorporates a collective learning strategy, the acquisition of personal and professional competencies will be facilitated.

\section{Negative aspects}

Both the questionnaire and interview findings revealed that participants associated peer observation with the potential for stress and anxiety. Despite the supportive evidence base for the use of peer observation, the literature also reflects upon the negative aspects of such schemes and mirrors similar concerns voiced by staff in this study findings (Hammersley-Fletcher and Orsmond 2005; Hatzipanagos and Lygo-Baker, 2006). As peer observation of practice is a form of evaluation, both observer and the observed are likely to experience some degree of anxiety within the process (Sweeney et al, 2001b). Anxiety in this context could lead to reluctance to participate, and according to Sweeney et al (2001b), therapists commonly experience a vulnerable sense of professional competence that could further intensify the anxiety of being observed. A number of other issues are subsequently raised, including the fact that peer observation by its very nature, is a form of judgment or requires some element of judgment from one individual in respect of another. One question raised in the findings was who is able to make an accurate decision about what constitutes good practice and the basis upon which they make that decision? Observation of one session alone can be disjointed and provide an incomplete picture as the session observed may link to other sessions. A further consideration is whether an observer can make meaningful comments if they are not a member of the same discipline or work within the same specialty (Shortland, 2004). This leads on to a discussion of the next key theme.

\section{Relationships in peer observation}

Findings revealed concern from participants about who would observe them in a peer observation scheme and how the relationship between certain observers and the observed may cause awkwardness and vulnerability. The issue of power relationships have been raised in the literature by HammersleyFletcher and Orsmond (2005) who suggest that observation should not be used in a judgmental way, yet neither should it be used to provide praise alone. Issues of bias could be eliminated if all observations were carried out by staff unknown to the observed although factors such as limited understanding of the discipline and context of the session could impact in other ways. In addition, where staff are unknown to each other there will be no relationship of trust as recommended by Hunter and Blair (1999). Cosh (1999) found staff concerns around friends being 'nice' to each other and avoiding critical appraisal would make feedback superficial, and limited the use of reflection.

In terms of the background of the observer, Beaty and McGill (1995) suggest that a peer from the same professional background may be able to provide an important professional perspective on the session. A peer from a different background may also have a valuable contribution to make from their professional perspective. It is important that early experience of peer observation is facilitated by a person with whom the observed feels comfortable and that constructive and supportive feedback is provided, which will in turn decrease anxiety for future observations (Hunter and Blair, 1999). There is divergent opinion about the impact of status, seniority and professional background (Gopee, 2001; Sweeney et al, 2001a) however, mutual trust and respect between both parties are paramount. Opportunities from the observation process will be maximized when all parties are willing to learn from each other and have the capacity to listen (Beaty and McGill, 1995). The National Association of Teachers in Further and 
Higher Education (2001) also recommend that the person being observed should choose the observer.

\section{Feedback}

Participants in the study expressed the strong need for sensitive and constructive feedback; a requirement that is supported by Peel (2005). Cosh (1999) states that the ability to provide constructive feedback is a considerable skill that requires training as there is scope to cause offence and hinder professional development when feedback is provided by staff with no professional training in this area. Swain (2007) also recommends that academics should be trained in peer observation so that feedback is handled assertively, although the author states that the provision of positive feedback alone is non-productive, and a lost opportunity for professional growth and the enhancement of practice.

In relation to negative feedback, Cosh (1999) discusses the idea that peer observation is or will be perceived to be a threatening and critical process, and questions to what extent practitioners will be motivated to improve their practice when they are told by another that their practice is wrong. To become defensive and resistive to comments and suggestions is a natural reaction and feedback itself is in effect, subjective and dependent upon the particular opinion of the observer. Beaty and McGill (1995) report that feedback given from the perspective of another needs to be carefully managed so as to avoid the person observed withdrawing from the process. Chappell (2007) states that the potential for progress and development is very much dependent upon the willingness of the individual to engage with the process and therefore those involved in reflective practice need to be open to alternative practice and strategies. An area of considerable delicacy that may require prior agreement in terms of procedure would be what course of action to take where poor or unsafe practice is observed and this issue is related to factors such as staff ownership of the peer observation process and the relationship between observed and observer.

Feedback may be most effective when provided following a period of reflection after the observation process and using a pre-agreed system such as a written feedback sheet. It is suggested that the person observed should take the lead in the provision of feedback.

\section{A system for peer review}

The authors sought the opinion of participants on whether and how a scheme of peer review in an educational, clinical or managerial context should be formally implemented. Findings revealed a strong desire from participants to have control over aspects of such a scheme, particularly over which session is observed and by who. Swain
(2007) discusses the need for ground rules regarding how a peer observation scheme is managed, suggesting that the observed and observer talk to each other beforehand and agree on what is to be observed. Swain states that although confidentiality between the pair must be ensured to enable frank discussion to take place, there may be general points that would be useful for consideration at departmental level. Ellis (2001) suggests that the peer observation process needs to be detailed and formalized, to the extent that there is a contract that outlines the responsibilities of both parties, that expectations are clearly set out and that clear guidelines are established. This view is reinforced by Cosh (1999) who suggests that it is vital that both parties understand the process and procedure to be used.

There are different suggestions as to the format that such observations may take, however, Shortland (2004) summarizes a general four-part process for observation:

Pre-observation meeting

The observation

A post-observation meeting

A record of the post-observation meeting.

In addition to the standard format of two staff observing each others practice, an alternative is a tri-partite method where three staff take part in the observation. Alternatively staff across a discipline or within a specialty can be used. One of the main concerns from staff in this study is that the process is best when it is voluntary and when the agenda is to provide mutual support. The overall aim of peer observation should be to provide a sense of security and an environment where staff can be openly self-reflective. Such an environment empowers staff to try new ways of working that will, in turn, enhance practice, rather than encourage an attitude of defensiveness and the continuance of old habits (Cosh, 1999). In essence, it is recommended that peer observation schemes should be developmental as opposed to judgmental (Shortland, 2004).

A final consideration is the impact of contextual issues that surround the implementation of a peer observation of practice scheme. The involvement of staff in the design and implementation of such a scheme is supported by these findings. The need to develop methods of observation recording and for staff to undergo training are all factors that have a resource implication which must be considered (Shortland, 2004).

It is clear that the successful development and continued practice of a peer observation of practice scheme either in an educational or practice context requires a complex interdependency of factors. Such factors include whether the scheme is voluntary or mandatory, staff ownership of the process at all stages, an agreed strategy for the procedure including 
who will observe and how often, what happens to the resulting feedback. The time, money and resources available within a department and of equal significance, the willingness for participants at all levels and throughout all stages to critically consider existing practice and long-held assumptions by applying a new viewing point to their practice must be taken into account (Larrivee, 2000).

As a result of staff discussions and the results of this study, staff at the study setting are expected to make informal arrangements for peer observation of practice and use or adapt existing university methods for recording the process. Discussion around implementing a more formal policy is ongoing.

\section{Areas for further research and project limitations}

This article presents only the first cycle of an action research project, however, from these findings, further cycles have been indicated. As the emergent themes are linked, so too are the possible future research action cycles. Further research could explore greater consideration of the strategies used by staff to support their ongoing professional development, how to evidence peer observation within CPD, deeper exploration into the issues and potential management of the negative aspects of peer observation and investigation of acceptable ground rules and how such a peer observation scheme will be put into operation.

As four questionnaires were not returned and only five staff participated in the interviews, the results cannot be said to accurately represent the whole directorate. In addition, according to Hammell et al (2002), the interpretation of results is subject to the views, biases and opinions of the researcher and may include the desire of the participant to please the interviewer, thereby limiting the generalizability of findings. When considering the issue of bias, the authors acknowledge the possible impact of drivers from a personal and directorate level to undertake research related to peer observation of practice. Hammell et al (2002) however, claims that such biases cannot be removed and that the investigator should not work towards making an interactive methodology neutral. To have made the research more rigorous, the interviews could have been typed up verbatim, and colleagues invited to self-select for interview rather than being asking to take part by the researcher.

\section{Project strengths}

Action research is linked to reflective practice and the exploration of practical everyday work (Schon, 1995). The adoption of this research strategy provides the opportunity to look, think and act (Stringer, 1999) while at the same time facilitated exploration of practical problems which are of professional concern in day-to-day work, the ultimate aim being to improve practice or bring about change. The Critical Emancipatory Action Research model promotes praxis among participants, linking the problem to the theory used to explain and solve it, empowering participants to identify problems and raise their collective awareness (Holter and Schwartz-Barcott, 1993).

By adopting this collaborate action research methodology, all staff were invited to participate in the questionnaires and therefore engage in self-reflective enquiry that is said to enable participants to better understand their practice and provide an opportunity to enhance the quality of their teaching. The use of this approach also facilitated staff engagement by involving colleagues in the compilation and modification of the questions used within both the questionnaire and interviews. The interviews generated detailed qualitative opinion from colleagues, particularly with regard to their fears and concern about peer observation. A significant level of honesty was reached when staff discussed feelings of vulnerability about peers making comment upon their practice and considered how this may impact upon relationships with colleagues. It was also noted that the themes generated from this study reflect those found within the literature.

The use of semi-structured interviews alongside questionnaires allowed both flexibility and the opportunity to follow-up individual drives and motives (Robson, 2002). This process also served as a form of triangulation and enhanced validity. This two-pronged approach to data collection provided greater depth of information and the project highlighted new cycles of action research as recommended by Kember (2000).

\section{CONCLUSIONS}

The results of this action research project provide an insight into the perceptions of staff working within a specific directorate in relation to the concept of a peer observation scheme being used to support professional development in a higher educational setting. By using action research as a methodology, staff were able to input into the research process as a means of self-reflective enquiry that has specific relevance to their practice (McNiff and Whitehead, 2006). Peer observation of practice is commended as a positive strategy to encourage reflection upon practice, facilitate developmental needs and promote good practice within higher education (HammersleyFletcher and Orsmond, 2005). The findings from this study reflect those themes found in relevant literature. Staff claimed to use a range of methods to support their professional development and for some staff, this includes observations, both formal 
and informal. Staff were aware of both positive and negative aspects of peer observation and although all participants stated that they were willing to engage with such a scheme, their concerns emphasized the need for more information, which could be established via further action research cycles. This study highlights the need for deeper exploration of strategies used by staff to enhance teaching practice, developing links between peer observation and CPD. Findings suggest that research focus should be centred on negative aspects of peer observation and ground rules for observation including how such a scheme could be formally implemented. IJTR

\section{Conflict of interest: none}

The authors would like to acknowledge the support provided by Viv Jones and all staff who contributed to the action research project, to the research supervisor and to the heads of school and department who were willing to support staff involvement in this project.

Bambino D (2002) Critical Friends. Educ Leadersh 59(6): $25-7$

Beaty L, McGill I (1995) Reflective practice - a developmental approach to observing teaching. Developing Reflective Practice. University of Brighton

Bell J (1999) Doing Your Research Project. 3rd edn. Open University Press, Buckingham

Biggs J (1999) Teaching For Quality Learning At University. 2nd edn. SRHE/OU Press, Buckingham

Blackmore JA (2005) A critical evaluation of peer observation via teaching observation within higher education. International Journal of Educational Management. 19(3): 218-32

Borton T (1970) Reach, Touch and Teach. McGraw Hill, New York

Boud D, Keogh R, Walker D (1985) Reflection: Turning Experience Into Learning. Kogan Page, London

Burnard P (1991) A Method of Analysing Interview Transcripts in Qualitative Research. Nurse Educ Today 11: 461-6

Chappell A (2007) Using Teaching Observations and Reflective Practice to Challenge Conventions and Conceptions of Teaching in Geography. Journal of Geography in Higher Education. 31(2): 257-68

College of Occupational Therapists (2002) Position Statement on Lifelong Learning. COT, London

Cosh J (1999) Peer Observation: A Reflective Model. ELT Journal 53(1): 22-7

Cotton AH (2001) Private thoughts in public spheres: issues in reflection and reflective practices in nursing. $J$ Adv Nurs 36(4): 512-19

Davys D, Jones V (2007) Peer observation: A tool for continuing professional development. International Journal of Therapy and Rehabilitation 14(11): 489-92

Department for Education and Skills (2003) The future of higher education. DfES, London. http://www.dfes.gov.uk/ hegateway/strategy/hestrategy/foreword.shtml (accessed 19 May 2008)

Department of Health (2004) The NHS Knowledge and Skills Framework (NHS KSF) and the Development Review Process. DH, London. http://www.dh.gov.uk/en/Publication sandstatistics/Publications/PublicationsPolicyAndGuidance/ DH_4090843 (accessed 19 May 2008)

Driscoll J, Teh B (2001) The potential of reflective practice to develop individual orthopaedic nurse practitioners and their practice. Journal of Orthopaedic Nursing 5: 95-103

Ellis G (2001) Looking at ourselves - Self assessment and peer assessment: Practice examples from New Zealand. Reflective Practice 2: 289-302

Gopee N (2001) The role of peer assessment and peer review in nursing. $B J N$ 10(2): 115-21

Hammell KW, Carpenter C, Dyck I, eds (2002) Using Oualitative Research, A Practical Guide for Occupational and Physical Therapists. Churchill Livingstone, London

Hammersley-Fletcher L, Orsmond P (2005) Reflecting on reflective practices within peer observation. Studies in Higher Education 30(2): 213-24

Hammersley-Fletcher L, Orsmond P (2004) Evaluating our peers: is peer observation a meaningful process? Studies in Higher Education 29(4): 439-503

Hatzipanagos S, Lygo-Baker S, (2006) Teaching observations: promoting development through critical reflection. Journal of Further and Higher Education 30(4): 421-31

Holter IM, Schwartz-Barcott D (1993) Action research: What is it? How has it been used in nursing? J Adv Nurs 18: $298-301$

Hunter EP, Blair EE (1999) Staff supervision for occupational therapists. British Journal of Occupational Therapy 62: 344-51

Kember D (2000) Action Learning and Action Research. Kogan Page, London

Kuit JA, Reay G (2001) Experiences of reflective teaching. Active Learning in Higher Education 2(2): 128-42

Larrivee B (2000) Transforming teaching practice: Becoming the critically reflective teacher. Reflective Practice 1(3) 293-307

McNiff J, Whitehead J (2006) All you need to know about action research. Sage, London

Martin G, Double J (1998) Developing Higher Education teaching skills through peer observation and collaborative reflection. Innovations in Education and Teaching International. 35(2): $161-70$

NATFHE (2001) Guidelines for Higher Education Branches: peer review and observation of teaching. Unpublished paper, NATFHE, London.

Peel D (2005) Peer observation as a transformatory tool? Teaching in Higher Education 10(4): 489-502

Polit DF, Beck CT, Hungler BP (2001) Essentials of Nursing Research, Methods, Appraisal and Utilisation. 5th edn. Lippincott. New York

Robson C (2002) Real World Research. 2nd edn. Blackwell Publishing, Oxford

Ruane JM (2005) Essentials of Research Methods. Blackwell Publishing, Oxford

Schon DA (1983) The Reflective Practitioner: How Professionals Think In Action. Temple Smith, London

Shortland S (2004) Peer Observation: a tool for staff development of compliance? Journal of Further and Higher Education 28(2): 219-28

Stringer ET (1999) Action Research: A Handbook For Practitioners, 2nd edn. Sage, Newbury Park

Swain C (2007) Has someone got their eye on you? The Times Higher Educational Supplement News report, 9th March

Sweeney G, Webley P, Treacher A (2001a) Supervision in Occupational Therapy, part 1: The Supervisor's Anxieties. British Journal of Occupational Therapy 64(7): 337-46

Sweeney G, Webley P, Treacher A (2001b) Supervision in Occupational Therapy, part 2: The Supervisee's Dilemma. British Journal of Occupational Therapy 64(8): 380-7

Tight M, ed (2004) The RoutledgeFalmer Reader In Higher Education. RoutledgeFalmer, London

\section{KEY POINTS}

- Reflective practice is required as evidence of quality education provision in higher education. Peer observation is recognized as an important tool for ensuring reflective practice.

There is a lack of published research on the use of peer observation by occupational therapists working in higher education.

- An action research project was undertaken to explore the perceptions of occupational therapy staff in a higher education department towards peer observation of practice and their opinions on potentially implementing a formalized system of peer observation.

- Findings suggest that staff, regardless of length of service, consider the process to be beneficial and would respond positively to the introduction of a formal scheme. However, participants also noted negative aspects to the process and emphasized the need for particular conditions for a formal scheme.

- Further research is suggested to explore negative aspects of peer observation and how a formal scheme should be implemented. 